\title{
Dual Circuitry for Odor-Shock Conditioning during Infancy: Corticosterone Switches between Fear and Attraction via Amygdala
}

\author{
Stephanie Moriceau, ${ }^{1}$ Donald A. Wilson, ${ }^{1}$ Seymour Levine,${ }^{2}$ and Regina M. Sullivan ${ }^{1}$ \\ ${ }^{1}$ Department of Zoology, University of Oklahoma, Norman, Oklahoma 73019, and 2Department of Psychiatry, University of California-Davis, Davis, \\ California 95817
}

\begin{abstract}
Rat pups must learn maternal odor to support attachment behaviors, including nursing and orientation toward the mother. Neonates have a sensitive period for rapid, robust odor learning characterized by increased ability to learn odor preferences and decreased ability to learn odor aversions. Specifically, odor- $0.5 \mathrm{~mA}$ shock association paradoxically causes an odor preference and coincident failure of amygdala activation in pups until postnatal day 10 (P10). Because sensitive-period termination coincides with a declining "stress hyporesponsive period" when corticosterone release is attenuated, we explored the role of corticosterone in sensitive-period termination. Odor was paired with $0.5 \mathrm{~mA}$ shock in either sensitive-period (P8) or postsensitive-period (P12) pups while manipulating corticosterone. We then assessed preference/aversion learning and the olfactory neural circuitry underlying its acquisition. Although sensitive-period control paired odor-shock pups learned an odor preference without amygdala participation, systemic $(3 \mathrm{mg} / \mathrm{kg}$, i.p.; $24 \mathrm{~h}$ and $30 \mathrm{~min}$ before training) or intra-amygdala corticosterone (50 or $100 \mathrm{ng}$; during training) permitted precocious odor-aversion learning and evoked amygdala neural activity similar to that expressed by older pups. In postsensitive-period (P12) pups, control paired odor-shock pups showed an odor aversion and amygdala activation, whereas corticosterone-depleted (adrenalectomized) paired odor-shock pups showed odor-preference learning and activation of an odor learning circuit characteristic of the sensitive period. Intra-amygdala corticosterone receptor antagonist (0.3 ng; during training) infused into postsensitive-period (P12) paired odor-shock pups also showed odor-preference learning. These results suggest corticosterone is important in sensitive-period termination and developmental emergence of olfactory fear conditioning, acting via the amygdala as a switch between fear and attraction. Because maternal stimulation of pups modulates the pups' endogenous corticosterone, this suggests maternal care quality may alter sensitive-period duration.
\end{abstract}

Key words: attachment; learning; corticosterone; stress; fear conditioning; olfaction; infant rat; sensitive period; olfactory bulb; piriform cortex; amygdala

\section{Introduction}

Infancy is characterized by rapid learning of orientation and approach to the caregiver, ensuring attachment to the caregiver. However, unique infant learning is also characterized by reduced aversion learning, perhaps to prevent learning to avoid the caregiver. For example, in classic experiments by Hess (1962), recently hatched chicks were shocked while presented with a surrogate mother. The next day, shocked chicks showed a stronger following response than unshocked chicks. In chicks a few hours older, similar pairings resulted in a subsequent aversion to the surrogate. Additional species exhibiting a similar phenomenon include nonhuman primates (Harlow and Harlow, 1965), dogs

Received Feb. 2, 2006; revised April 11, 2006; accepted May 17, 2006

This work was supported by National Institute of Child Health and Human Development Grant HD33402, National Science Foundation Grant IBN0117234, Oklahoma Center for Advancement of Science, and University of Oklahoma Research Funds to R.M.S. We thank Kavita Trivedi for assistance in this project. We also thank Dean Myers and Ari Berkowitz for comments on a previous draft of this manuscript.

Correspondence should be addressed to Dr. Stephanie Moriceau, Department of Zoology, University of Oklahoma, 730 Van Vleet Oval, Norman, 0K 73019. E-mail: smoriceau@ou.edu.

DOI:10.1523/JNEUROSCI.0499-06.2006

Copyright $\odot 2006$ Society for Neuroscience $\quad$ 0270-6474/06/266737-12\$15.00/0
[Fisher (1955), cited in Rajecki et al. (1978)], and humans (Helfer et al., 1997). Our imprinting model in rat pups uses a fearconditioning paradigm in which odor paired with $0.5 \mathrm{~mA}$ shock paradoxically causes an odor preference during a temporally defined sensitive period (Sullivan et al., 1986a,b, 2000a; Camp and Rudy, 1988; Moriceau and Sullivan, 2004b; Roth and Sullivan, 2005), although pups clearly show pain-related responses during shock (Stehouwer and Campbell, 1978; Emerich et al., 1985; Barr, 1995; Sullivan et al., 2000a). Our data suggest the amygdala does not participate in the sensitive-period odor-shock conditioning that may underlie the pups' attenuated aversion learning (Sullivan et al., 2000a; Moriceau and Sullivan, 2004b; Roth and Sullivan 2005).

Here we explore the termination of sensitive-period learning as characterized by the emergence of "adult-like" fear learning from odor-shock conditioning. Our assessment began with the stress hormone corticosterone (CORT) for the following reasons. First, the sensitive period is related to the "stress hyporesponsive period" when the pups' low CORT level is not raised by most stressful stimuli (i.e., restraint, shock) (Rosenfeld et al., 1992; Grino et al., 1994; Levine, 2001). Second, both unlearned fear, 
such as the pups' freezing (immobilization) response to unfamiliar male odor, and the activation of the amygdala by predator odor emerge as the sensitive period ends (Takahashi et al., 1991; Takahashi, 1992; Weidenmayer and Barr, 2001; Moriceau et al., 2004). Predator odor-induced freezing and coincident amygdala activation can be evoked precociously by injecting CORT in sensitive-period pups (Takahashi et al., 1991; Takahashi, 1992; Weidenmayer and Barr, 2001; Moriceau et al., 2004). Third, adrenalectomizing pups can prolong the infants' unique sensitive-period learning, such as attenuated fear and inhibitory conditioning (Collier et al., 1979; Blozovski and Cudennec, 1980; Bialik et al., 1984; Myslivecek, 1997; Moriceau and Sullivan, 2004b), as well as extend the learning-induced changes of the olfactory bulb characteristic of the sensitive period (Moriceau and Sullivan, 2004b). Fourth, sensitive-period odor-shockinduced preference learning and its olfactory bulb neural correlates can be blocked by a single injection of CORT, although pups did not learn to avoid the odor (Moriceau and Sullivan, 2004b).

Here we extend our sensitive-period CORT manipulations to two systemic injections ( $24 \mathrm{~h}$ and $30 \mathrm{~min}$ before conditioning). We found that pups in the sensitive period exhibit adult-like fear conditioning along with amygdala participation and emergence of the adult-like olfactory learning circuit (posterior piriform cortex and specific amygdala nuclei). Intra-amygdala CORT infusion limited to the acquisition period also precociously produced an odor aversion in sensitive-period pups, which suggests the amygdala is the site of CORT action in sensitive-period termination. Finally, depletion of CORT or intra-amygdala infusion of a CORT antagonist in older postsensitive-period pups reinstates the sensitive-period shock-induced odor-preference learning and its associated non-amygdala learning circuit.

\section{Materials and Methods}

Subjects. The subjects were postnatal day 8 (P8) and P12 male and female Long-Evans rat pups born and bred in our colony (originally from Harlan Lab Animals, Indianapolis, IN). Dams were housed in polypropylene cages $(34 \times 29 \times 17 \mathrm{~cm})$ lined with pine shavings and kept in a room controlled for temperature $\left(23^{\circ} \mathrm{C}\right)$ and light (7:00 A.M. to 7:00 P.M.). Food and water were available ad libitum. The day of parturition was considered $\mathrm{P} 0$, and litters were culled to 12 on $\mathrm{P} 0-\mathrm{P} 1$. No more than one male and one female from a litter were used in each experimental condition. All procedures were approved by the University of Oklahoma Institutional Animal Care and Use Committee and followed National Institutes of Health guidelines.

Odor-shock conditioning. At P8 or P12, pups were assigned to one of the following 45 min classical conditioning groups: (1) paired odorshock, (2) unpaired odor-shock, and (3) odor-only. Pups were trained in individual $600 \mathrm{ml}$ plastic beakers and were given a $10 \mathrm{~min}$ adaptation period to recover from experimental handling. During a $45 \mathrm{~min}$ training session, pups received 11 presentations of a $30 \mathrm{~s}$ peppermint odor [conditioned stimulus (CS)] and a $1 \mathrm{~s}, 0.5 \mathrm{~mA}$ tail shock (conditioned stimulus), with an intertrial interval of $4 \mathrm{~min}$. Peppermint odor was delivered by a flow dilution olfactometer ( 2 liters/min flow rate) at a concentration of 1:10 peppermint vapor. Paired odor-shock pups received 11 pairings of the $30 \mathrm{~s}$ odor with shock overlapping during the last $1 \mathrm{~s}$ of the odor presentation. Unpaired odor-shock pups received the shock 2 min after each odor presentation. Odor-only pups received only the peppermint odor presentations.

To verify learning and ensure CORT injections did not disrupt the pups' responsiveness to either the odor or shock, behavioral responsiveness to the stimuli presentations were recorded and acquisition curves were constructed. Responses of these motorically immature animals were recorded by noting the number of limbs moving $(0=$ no movement of the extremities; $5=$ movement of all five extremities that includes the head), as well as specific behaviors (i.e., head up for response to odor, wall climbing and vocalization to shock). Observations were made $20 \mathrm{~s}$ before the odor presentation, the first $20 \mathrm{~s}$ of the odor presentation, and the $1 \mathrm{~s}$ shock delivery (Hall, 1979; Sullivan et al., 1994; Moriceau and Sullivan, 2004b).

Systemic CORT. P8 and P12 pups were given injections of either CORT $(3.0 \mathrm{mg} / \mathrm{kg}$, i.p.) or saline (Takahashi, 1994; Moriceau and Sullivan, $2004 \mathrm{~b}$ ) either once (30 min before training) or twice ( $24 \mathrm{~h}$ and $30 \mathrm{~min}$ before training). Two injections were used (1) to expose the glucocorticoid receptors (GRs) to a more prolonged occupation by CORT and (2) also because CORT clearance is much slower in pups and the $24 \mathrm{~h}$ CORT would remain in the system longer. For postsensitive-period assessment of CORT, endogenous CORT was removed by adrenalectomy (ADX) at $\mathrm{P} 8$ for training of $\mathrm{P} 12$ pups. Pups were anesthetized using isoflurane, and dorsal incisions were made to extract the adrenal glands. Sham-operated controls received dorsal incisions, but the adrenal glands were left intact. After recovery from surgery $(\sim 1 \mathrm{~h})$, pups were returned to the mother and left undisturbed until training (Moriceau and Sullivan, 2004b). CORT receptors (mineralocorticoid receptor and GR) are present throughout both the adult and infant brain (Rosenfeld et al., 1993).

Radioimmunoassay. The levels of circulating CORT were determined from heart blood of P8 and P12 pups with or without shock. Blood samples were centrifuged at 14,000 rpm for $6 \mathrm{~min}$. Plasma was stored at $-70^{\circ} \mathrm{C}$ until radioimmunoassay (RIA) was performed. Duplicate plasma samples were analyzed for CORT using the Rat CORT Coat-a-Count kit (Radioassay Systems Labs, Carson, CA). The sensitivity of the assay was 5 $\mathrm{ng} / \mathrm{ml}$. The intra-assay coefficient of variation was $1-9 \%$.

Based on RIA done in our laboratory, the $3.0 \mathrm{mg} / \mathrm{kg}$ dose of CORT produces CORT levels similar to those found in nonmaternally deprived and stressed (endotoxin injection) pups at P6 (Dent et al., 1999; Moriceau and Sullivan, 2004b).

Surgery and amygdala/caudate infusion. On P5-P6 or P10-P11, pups were anesthetized by inhalation with isoflurane and placed in an adult stereotaxic apparatus modified for use with infants. Stainless steel cannulas (30 gauge tubing) were implanted bilaterally in the amygdaloid complex or caudate through holes drilled in the overlying skull. Stereotaxic coordinates, derived from an atlas and previous work from our laboratory (Paxinos et al., 1991; Sullivan and Wilson, 1993), were used for implanting cannulas into the amygdaloid complex (P5-P6: caudal, $-0.80 \mathrm{~mm}$; lateral, $\pm 3.00 \mathrm{~mm}$ from bregma; or P10-P11: caudal, -0.90 $\mathrm{mm}$; lateral, $\pm 4.50 \mathrm{~mm}$ from bregma) or the caudate nucleus (caudal, $+0.4 \mathrm{~mm}$; lateral, $\pm 1.2 \mathrm{~mm}$ from bregma). The cannulas were lowered $5.0 \mathrm{~mm}$ (P5-P6) or $6.0 \mathrm{~mm}$ (P10-P11) for the amygdala and $2.5 \mathrm{~mm}$ (P5-P6) or $3.0 \mathrm{~mm}(\mathrm{P} 10-\mathrm{P} 11)$ for the caudate from the surface of the skull, placing the tip near the amygdala or the caudate. The cannulas were fixed to the skull with dental cement. To ensure patency of the cannulas, guide wires were placed in the lumen of the tubing until training. After recovery from surgery (generally within $30 \mathrm{~min}$ ), pups were returned to the dam and littermates for a $2 \mathrm{~d}$ recovery period until conditioning. On P7-P8 or P12-P13, pups were placed in individual $600 \mathrm{ml}$ plastic beakers. Their bilateral cannulas were attached via PE10 tubing to a Harvard syringe pump driving two Hamilton microliter syringes. The cannulas were filled (16 s at $0.5 \mu \mathrm{l} / \mathrm{min}$ ) with CORT (50 or $100 \mathrm{ng}$, P7-P8 pups; Sigma, St. Louis, MO), GR antagonist mifepristone (RU 38486; 0.3 ng, P12-P13 pups; Sigma), or cholesterol (control; Sigma). Pups were odorshock conditioned as described above. During the first 20 min training period, pups received drug or control solution infused at $0.1 \mu \mathrm{l} / \mathrm{min}$, for a total infusion volume of $2.0 \mu \mathrm{l}$ as described previously (Sullivan et al., 1992, 2000b; Moriceau and Sullivan, 2004a). After training, pups were disconnected from the syringe pump and returned to the nest until testing the following day.

GR antagonist RU 38486 doses were chosen similar to adult doses (Conrad et al., 2004; Donley et al., 2005; Yang et al., 2005): (1) the GR number shows a marked increase from birth to P12 pups (65\% of adult levels) (Rosenfeld et al., 1988, 1993) and (2) the pharmacological profile (affinity for CORT) of GR in brain seems to be quite similar between P12 pups and adult (Rosenfeld et al., 1988; Meaney et al., 1988; Walker et al., 2002).

Verifying cannula placement and CORT spread in amygdala. After testing, brains were removed, frozen, sectioned $(20 \mu \mathrm{m})$ in a $-20^{\circ} \mathrm{C}$ cryostat, and cresyl violet stained for identification of the cannula placement in 
relation to amygdala nuclei or the caudate nucleus using a neonatal atlas (Paxinos et al., 1991). To characterize the extent of drug diffusion within and outside of the amygdaloid complex, additional pups were implanted, with the same surgical and drug infusion paradigms. These additional pups were infused with $2 \mu \mathrm{l}$ of a saline solution of $\left[{ }^{3} \mathrm{H}\right] \mathrm{CORT}(1 \mu \mathrm{Ci} / \mu \mathrm{l}$; NEN Research Products, Boston, MA). Twenty minutes after infusion, the brains were quickly removed, frozen in 2 -methylbutane at $-45^{\circ} \mathrm{C}$, and sliced in $20 \mu \mathrm{m}$ coronal sections. The slides were apposed to a tritium storage phosphor screen (Amersham Biosciences, Piscataway, NJ). After $14 \mathrm{~d}$ exposure, the screen was scanned at a pixel density of $50 \mu \mathrm{m}(5000$ dots per square centimeter) with a STORM 820 PhosphorImager (Molecular Dynamics, Sunnyvale, CA). Phosphorimaging of the slides results in a TIFF image file for analysis of ${ }^{3} \mathrm{H}$ diffusion (Tucker et al., 2002; Moriceau and Sullivan, 2004a).

Assessing the neural circuitry involved in pup olfactory learning. P8 and $\mathrm{P} 12$ pups were given injections of ${ }^{14} \mathrm{C}$ 2-deoxyglucose (2-DG; $20 \mu \mathrm{Ci} /$ $100 \mathrm{~g}$, s.c.) $5 \mathrm{~min}$ before the $45 \mathrm{~min}$ odor-shock conditioning. Immediately after conditioning, pups were decapitated and their brains were quickly removed, frozen in 2 -methylbutane $\left(-45^{\circ} \mathrm{C}\right)$, and stored in a $-70^{\circ} \mathrm{C}$ freezer. For analysis, brains were sectioned $(20 \mu \mathrm{m})$ in a $-20^{\circ} \mathrm{C}$ cryostat, and every other section was saved to be placed on a coverslip and exposed for $5 \mathrm{~d}$ along with ${ }^{14} \mathrm{C}$ standards $\left({ }^{14} \mathrm{C}\right.$ standards, $10 \times 0.02 \mathrm{mCi}$; American Radiolabeled Chemicals, St. Louis, MO) to x-ray film (DiRocco and Hall, 1981; Coopersmith and Leon, 1986; Sullivan and Wilson, 1995; Nudo and Masterton, 2004).

Specific amygdala nuclei are not easily detected with 2-DG and were identified by counterstaining each 2-DG section with cresyl violet, which was than used to make an overlay for the 2-DG autoradiography. While the amygdala continues to develop through adolescence, nuclei are distinct by P7 and responsive to olfactory information during the early neonatal period (Schwob et al., 1984; Berdel et al., 1997; Morys et al., 1999; Nair and Gonzalez-Lima, 1999; Berdel and Morys, 2000; Bouwmeester et al., 2002; Wilson, 2003). However, at this age, minimal connections exist between the amygdala and other brain areas considered important in fear conditioning, such as the prefrontal cortex and hippocampus (Nair and Gonzalez-Lima, 1999; Bouwmeester et al., 2002).

The 2-DG uptake was expressed relative to 2-DG uptake in the corpus callosum (which did not vary with conditioning group) to control for differences in section thickness and exposure (Sullivan et al., 2000a). Brain areas examined were the anterior olfactory nucleus (AON) (medial, lateral, ventral, and dorsal nucleus), anterior and posterior piriform cortex, and basolateral/lateral, cortical, medial, and central amygdaloid nuclei.

$Y$-maze to assessing learning. The day after conditioning, pups were given a behavioral Y-maze test. Pups used in behavioral tests were generally littermates of pups used for neural analysis and trained together. This test required pups to choose between two arms of a Plexiglas Y-maze (start box, $8.5 \mathrm{~cm}$ width $\times 10 \mathrm{~cm}$ length $\times 8 \mathrm{~cm}$ height; choice arms, $8.5 \times 24 \times 8 \mathrm{~cm})$, one containing the peppermint odor CS $(20 \mu \mathrm{l}$ of peppermint odor on a KimWipe placed at the end of the alley) and the other containing the familiar odor of pine shavings ( $20 \mathrm{ml}$ of clean shavings in a Petri dish placed at the end of the alley). The start box was separated from the alleys by two doors. A pup was placed in the start box for $5 \mathrm{~s}$ before the door to each alley was opened. Each pup was given $60 \mathrm{~s}$ to choose an arm. A response was considered a choice when a pup's entire body was past the entrance to the alley. Pups received five sequential trials with $30 \mathrm{~s}$ between trials, and the floor was cleaned between each trial (Sullivan and Wilson, 1991). Observation during the testing was done blind to the training condition.

Statistical analysis. Comparisons were made between groups using the ANOVA test, followed by post hoc Fisher's tests (Winkler and Hays, 1975).

\section{Results}

\section{P8 and P12 CORT response to shock}

As shown in Figure 1, P12 but not P8 pups receiving shock (same shock schedule as conditioning) showed a significant increase in the CORT level. ANOVA analysis revealed a main effect of age $\left(F_{(1,9)}=15.603 ; p<0.005\right)$ and shock $\left(F_{(1,9}=7.497 ; p<0.05\right)$;

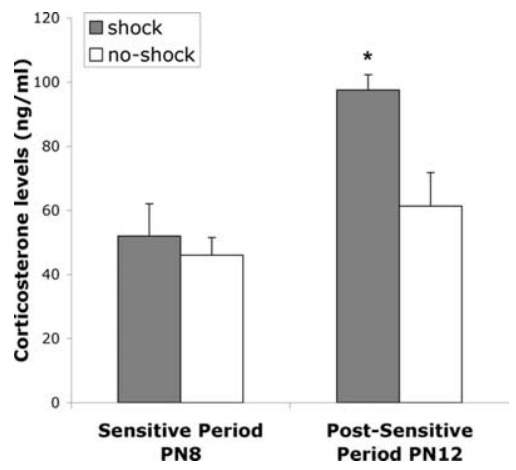

Figure 1. Mean ( \pm SEM) CORT levels shown in nanograms per milliliter for sensitive-period postnatal day 8 (PN8) pups and postsensitive-period PN12 pups comparing control animals with animals receiving shock. ${ }^{*} p<0.05$, significant difference from each of the other groups.
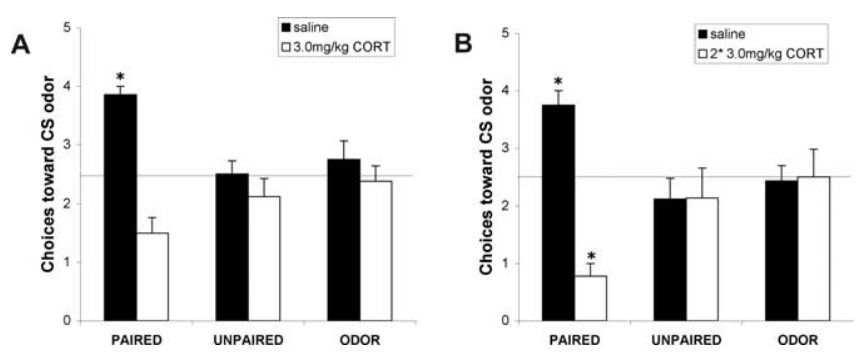

Figure 2. Mean ( \pm SEM) number of choices toward the CS odor during the Y-maze test (total of five trials) for sensitive-period P8 pups receiving a single CORT injection $(\boldsymbol{A})$ and sensitiveperiod P8 pups receiving a double CORT injection $(\boldsymbol{B}) .{ }^{*} p<0.05$, significant difference from each of the other groups.

post hoc Fisher's tests $(p<0.05$ level) revealed that P12 pups receiving a shock had significantly higher CORT levels compared with all other groups at both ages.

\section{Increased CORT during the sensitive period permits odor-aversion learning}

At P8, paired odor-shock pups given injections of saline learned an odor preference, whether given one or two injections of saline (Fig. 2). Paired pups that received one injection of CORT $30 \mathrm{~min}$ before odor-shock conditioning (Fig. 2A) did not learn either an odor preference or aversion, suggesting CORT disrupted learning and replicating our previous results (Moriceau and Sullivan, $2004 \mathrm{~b}$ ). However, double injections of CORT (24 h and $30 \mathrm{~min}$ before paired odor-shock conditioning) (Fig. $2 B$ ) prematurely terminated the sensitive period for odor-preference learning and permitted pups to learn an odor aversion instead.

The single CORT injection ANOVA analysis revealed a main effect of drug treatment $\left(F_{(1,39)}=22.570 ; p<0.0001\right)$ and a significant interaction between the training condition and drug treatment $\left(F_{(2,39)}=9.237 ; p<0.001\right)$; post hoc Fisher's tests revealed that the saline-paired groups differed significantly from each of the control groups at the $p<0.05$ level, whereas the 3.0 $\mathrm{mg} / \mathrm{kg}$ CORT-paired group was not significantly different from control groups (Fig. 2A).

The double CORT injection ANOVA analysis revealed a main effect of drug treatment $\left(F_{(1,41)}=11.467 ; p<0.01\right)$ and a significant interaction between the training condition and drug treatment $\left(F_{(2,41)}=13.099 ; p<0.0001\right)$; post hoc Fisher's tests revealed that the saline-paired group and the double CORT-paired groups each differed significantly from each of the control groups at the $p<0.05$ level (Fig. $2 B$ ). 
A

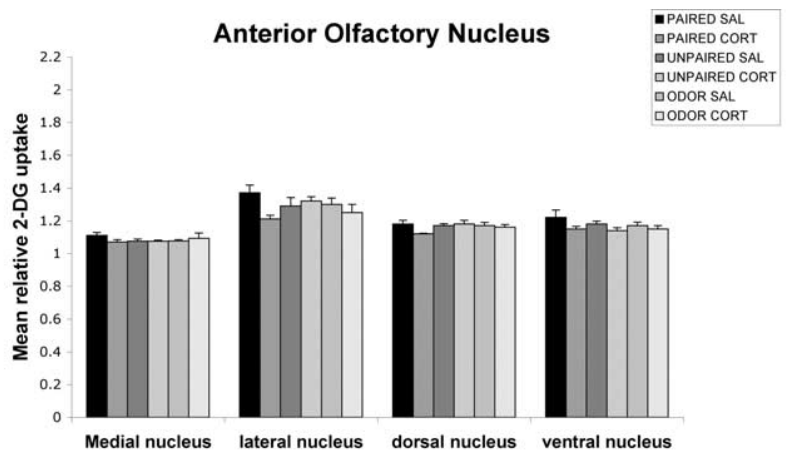

B

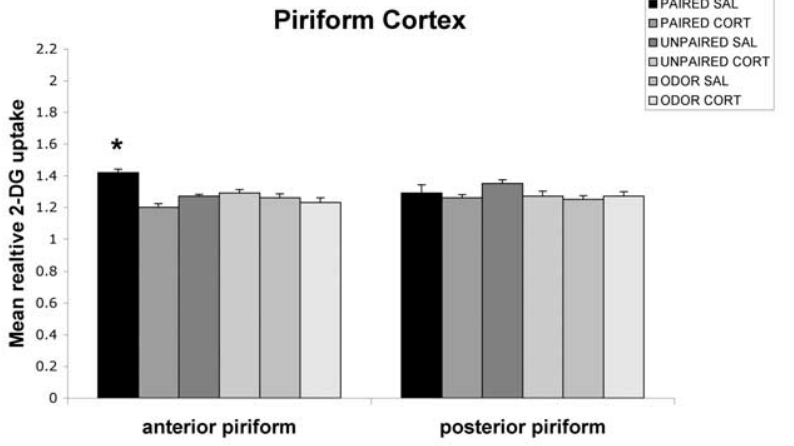

C

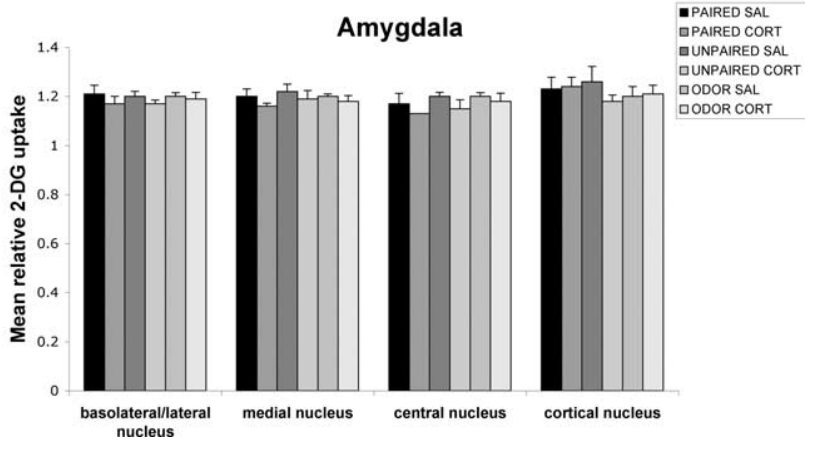

Figure 3. Effect of a single CORT injection on the 2-DG relative uptake in neonate (P8) olfactory circuitry. Error bars represent the mean ( \pm SEM) level of 2-DG uptake in the medial, lateral, dorsal, and ventral nuclei of the AON $(\boldsymbol{A})$, anterior and posterior piriform cortex $(\boldsymbol{B})$, and basolateral/lateral, medial, central, and cortical nuclei of the amygdala (C). ${ }^{*} p<0.05$, significant difference from all other groups. SAL, Saline.

Increased CORT during the sensitive period produces circuit activation similar to postsensitive period animals

As illustrated in Figures 3 and 4, saline-treated sensitive-period (P8) paired odor-shock pups had learning-induced enhancement in the anterior piriform cortex activity, which replicates previous results (Roth and Sullivan, 2005). As shown in Figure 3, at P8, one injection of CORT 30 min before odor-shock conditioning, which disrupts behavioral learning (Fig. $2 \mathrm{~A}$ ), also prevented learning-associated changes in the anterior piriform cortex. In contrast, as illustrated in Figure 4, double CORT injections ( $24 \mathrm{~h}$ and $30 \mathrm{~min}$ before conditioning), which cause pups to learn an odor aversion rather than the age-typical odor preference (Fig. $2 B$ ), produced odor-shock-induced enhancement in the posterior piriform cortex and amygdala activity (cortical, basolateral/ lateral, and medial nuclei). Thus, it seems that double CORT injection during the sensitive period (P8) was sufficient to allow odor-shock activation of the neural circuitry underlying odorshock aversion learning normally expressed in postsensitiveperiod pups.
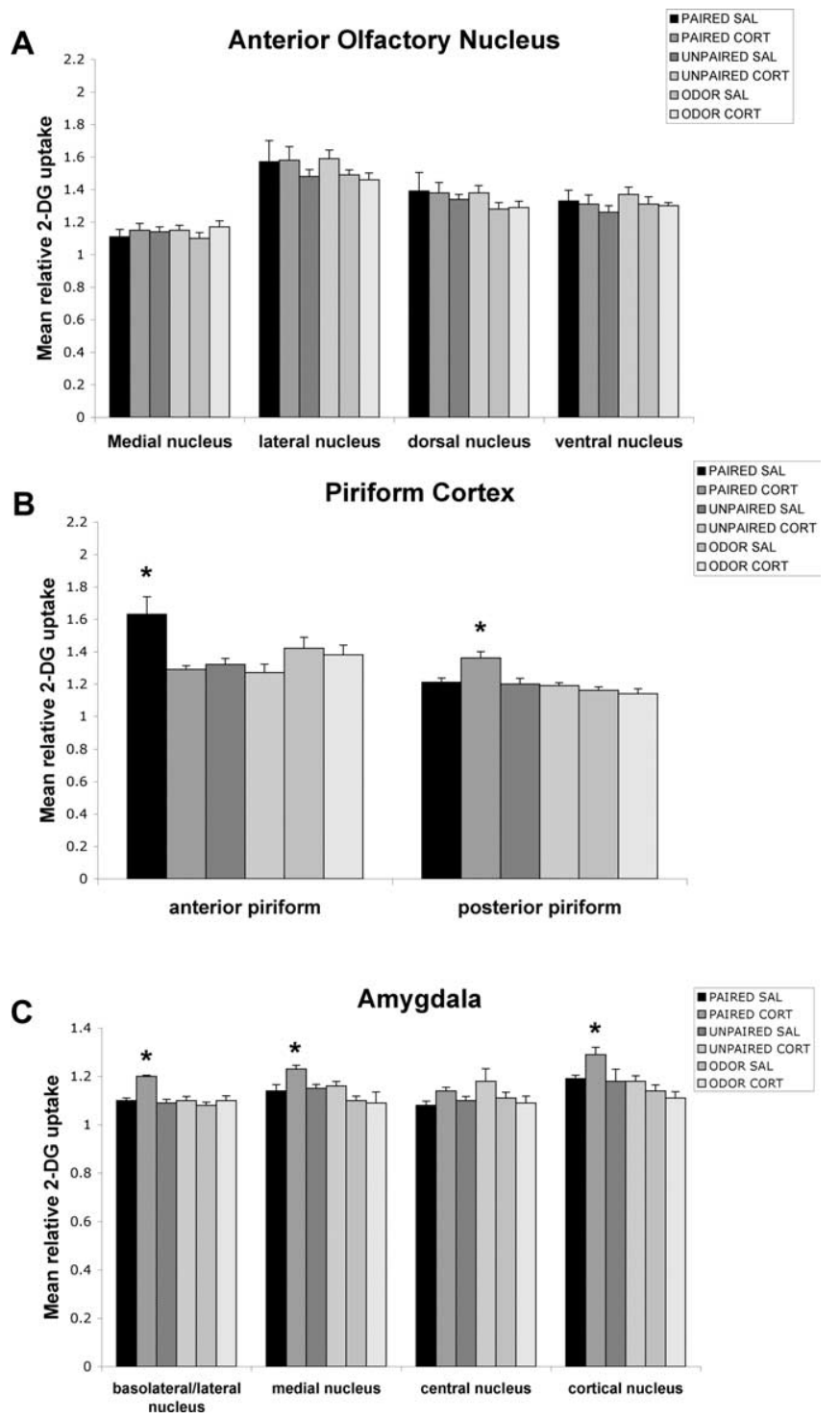

Figure 4. Effect of a double CORT injection on the 2-DG relative uptake in neonate (P8) olfactory circuitry. Error bars represent the mean ( \pm SEM) level of 2-DG uptake in the medial, lateral, dorsal, and ventral nuclei of the $A 0 N(\boldsymbol{A})$, anterior and posterior piriform cortex $(\boldsymbol{B})$, and basolateral/lateral, medial, central, and cortical nuclei of the amygdala (C). ${ }^{*} p<0.05$, significant difference from all other groups. SAL, Saline.

As illustrated in Figure 3, one CORT injection prevent the significant enhancement in the anterior piriform cortex $\left(F_{(5,22)}=\right.$ 11.664; $p<0.0001)$. Post hoc Fisher's tests indicated that the saline-paired group differed significantly from each of the other paired groups and each control group at $p<0.05$ levels for the anterior piriform cortex. No statistical differences were found for the AON, posterior piriform cortex, basolateral/lateral amygdala, medial amygdala, central amygdala, or cortical amygdala.

As shown in Figure 4, the double CORT injection caused a significant enhancement in odor-shock-induced activation of the posterior piriform cortex $\left(F_{(5,21)}=7.297 ; p<0.0005\right)$, basolateral/lateral amygdala $\left(F_{(5,23)}=12.004 ; p<0.0001\right)$, cortical amygdala $\left(F_{(5,19)}=4.186 ; p<0.01\right)$, and medial amygdala $\left(F_{(5,20)}\right.$ $=5.221 ; p<0.005)$. Post hoc Fisher's tests revealed that the anterior piriform cortex of paired saline pups differed from each of the other groups (similar to saline pups in the CORT oneinjection experiment), whereas the paired double CORT group differed from the other groups for the posterior piriform, baso- 


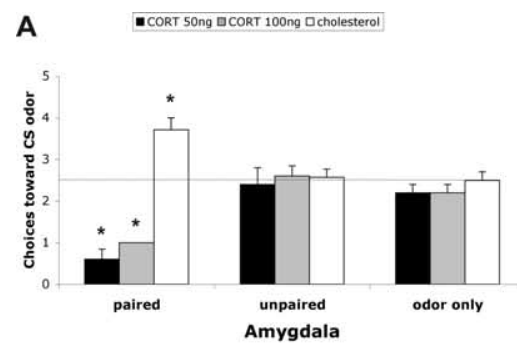

C
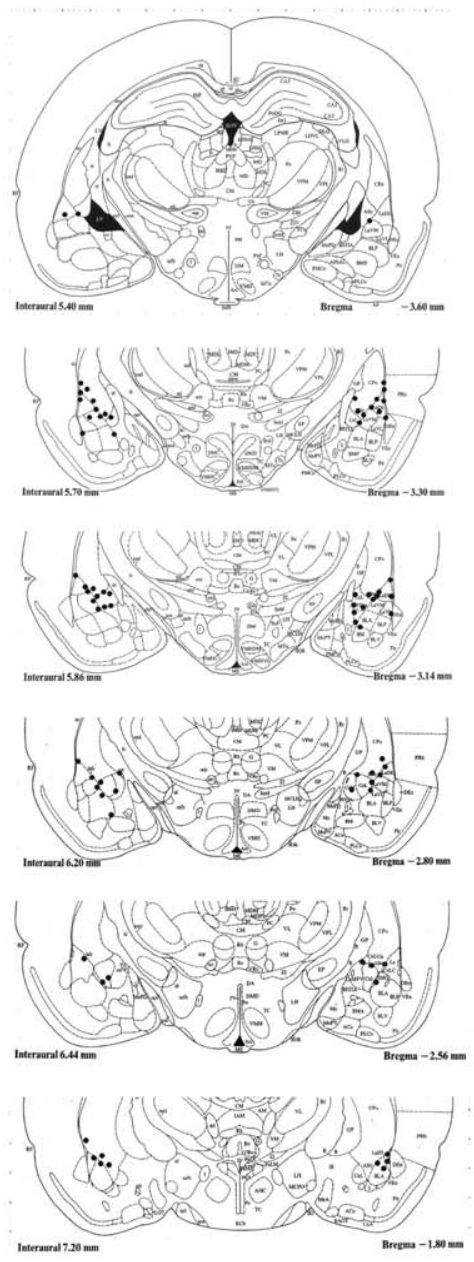

E

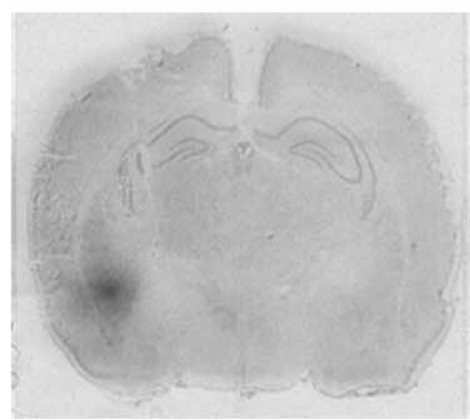

B

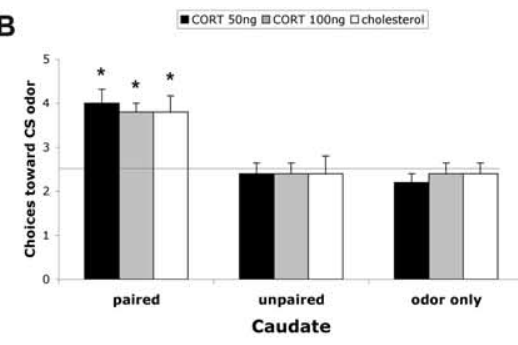

D
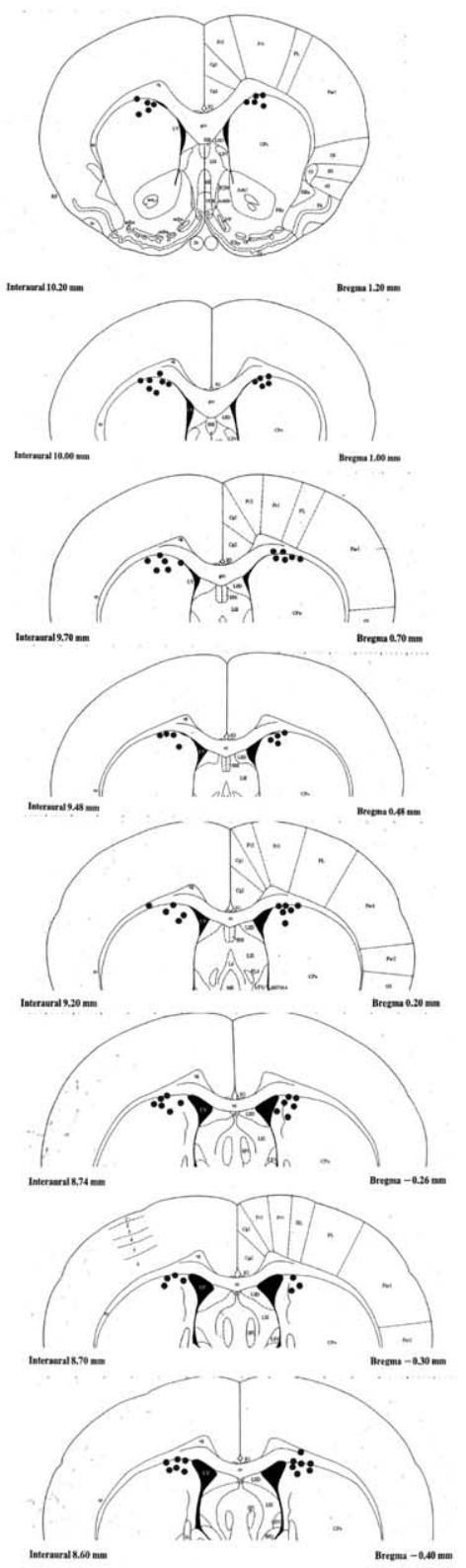

Figure 5. A, Mean ( \pm SEM) number of choices toward the CS odor during the Y-maze test. Training infusion of amygdala CORT permitted the learning of a relative odor aversion compared with each of the other groups. $\boldsymbol{B}$, Mean ( \pm SEM) number of choices toward the CS odor during the Y-maze test. Training infusion of caudate CORT permitted the learning of a relative odor preference compared with each of the other groups. In $\boldsymbol{A}$ and $\boldsymbol{B}$, the asterisks indicate significant differences from the control groups ( $p<$ 0.001). C, Locations of cannula tips (solid circles) in rats used for CORT infusion into the amygdala. $\boldsymbol{D}$, Locations of cannula tips (solid circles) in rats used for CORT infusion into the caudate. $\boldsymbol{E}$, Section from a P8 pup counterstained with cresyl violet and characterizing the extent of $\mathrm{H}^{3} \mathrm{CORT}$ drug diffusion within the amygdala.

lateral/lateral amygdala, cortical amygdala, and medial amygdala at the $p<0.05$ level. No statistically significant difference was found for the AON.

\section{Intra-amygdala infusion of CORT during the sensitive period permits odor-aversion learning}

As shown in Figure $5 A$, control pups, with vehicle infused into the amygdala during the sensitive period (P8) showed agetypical odor-preference learning. However, sensitive-period pups given 50 or 100 ng of CORT directly infused into the amygdala during paired odor-shock conditioning exhibited a subsequent, precocious learned aversion for the peppermint odor. Control infusions of CORT into the caudate are shown in Figure $5 B$ and illustrate sensitive-period pups given 50 or 100 ng of intra-caudate CORT during paired odor-shock conditioning still demonstrated age-typical odor-preference learning. ANOVA analysis for the amygdala infusion revealed a significant main effect of training condition $\left(F_{(2,41)}=7.318 ; p<\right.$ $0.005)$, a main effect of drug treatment $\left(F_{(2,41)}=21.694 ; p<0.0001\right)$, and a significant interaction between the training condition and drug treatment $\left(F_{(4,41)}=\right.$ 15.183; $p<0.0001)$; post hoc Fisher's tests revealed that pups infused with 50 or 100 ng of CORT into the amygdala spent significantly less time over the CS odor than each of the other groups $(p<0.05)$. ANOVA analysis for the caudate infusion revealed a significant main effect of training condition $\left(F_{(2,36)}=28.167 ; p<\right.$ $0.0001)$; post hoc Fisher's tests revealed that pups infused with 50 or $100 \mathrm{ng}$ of CORT into the caudate still showed an odor preference compared with the control groups $(p<0.05)$. Analysis of activity (first $20 \mathrm{~s}$ of odor) during odor-shock conditioning with amygdala or caudate infusion demonstrated that the acquisition curves were significantly different for trial by condition (data not shown; repeated-measure ANOVA; amygdala: $F_{(20,410)}=6.711, p<$ 0.0001 ; caudate: $F_{(20,360)}=11.488, p<$ 0.0001 ) but not for trial by drug (amygdala: $F_{(20,410)}=0.667, p=0.8586$; caudate: $\left.F_{(20,360)}=0.950, p=0.5239\right)$. Cannula tip placements at the amygdala and the caudate were verified, and all tip placements were within $1 \mathrm{~mm}$ of the amygdala and targeted the basolateral nucleus, the lateral nucleus, or the central nucleus of the amygdala and the caudate (Fig. 5C,D). The analysis of ${ }^{3} \mathrm{H}$ CORT diffusion showed infused volumes primarily limited to the amygdala and immediate peri-amygdala region (Fig. 5E). 
A

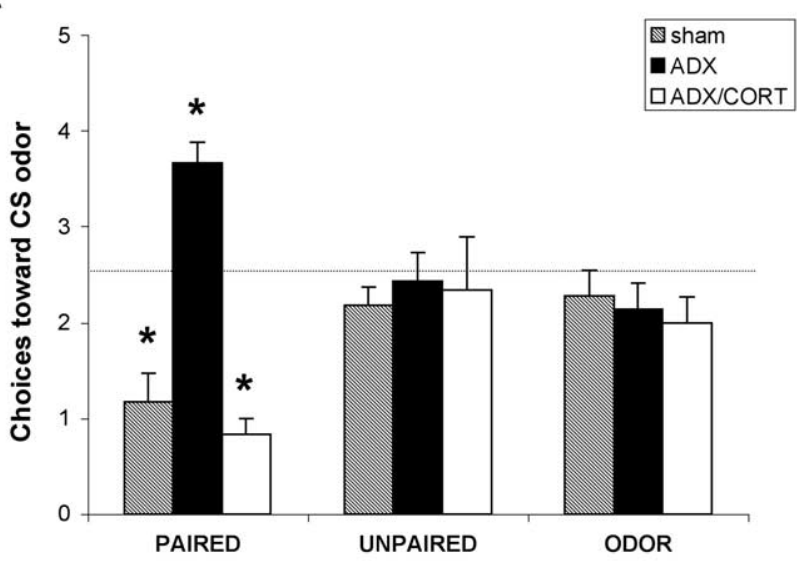

B

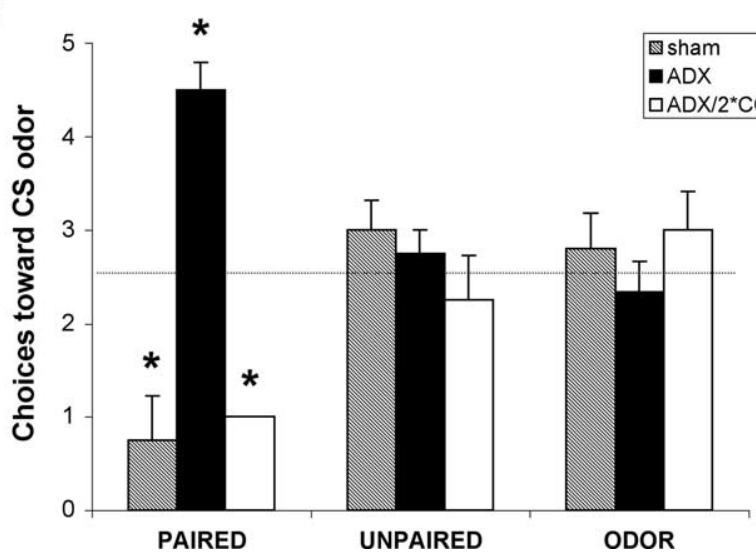

Figure 6. Mean ( \pm SEM) number of choices toward the CS odor during the $Y$-maze test (total of five trials) for postsensitive-period P12 pups receiving a single CORT injection $(\boldsymbol{A})$ and postsensitive-period P12 pups receiving a double CORT ( $2^{*}$ CORT) injection $(\boldsymbol{B}) .{ }^{*} p<0.05$, significant difference from all other groups.

Decreasing CORT (ADX) extends the sensitive-period learning, and replacement CORT reinstates aversion learning At P12, sham-ADX-paired odor-shock pups learned an odor aversion (Fig. 6). Pups that received ADX (removal of endogenous CORT) before paired odor-shock conditioning (Fig. 6) showed an extension of the sensitive period and permitted pups to learn to approach odors paired with $0.5 \mathrm{~mA}$ shock rather than the age-typical-learned odor avoidance. ADX pups that received CORT replacement with one injection of CORT (30 min) (Fig. $6 \mathrm{~A}$ ) or with two injections of CORT ( $24 \mathrm{~h}$ and $30 \mathrm{~min}$ ) (Fig. $6 \mathrm{~B}$ ) before paired odor-shock conditioning learned to avoid odors paired with $0.5 \mathrm{~mA}$ shock.

The single CORT injection ANOVA analysis showed a significant effect of drug treatment $\left(F_{(2,61)}=10.231 ; p<0.0005\right)$ and a significant interaction between the training condition and drug treatment $\left(F_{(4,61)}=8.724 ; p<0.0001\right)$; post hoc Fisher's tests revealed that the sham, ADX plus CORT, and ADX-paired groups were significantly different from each of the control groups at the $p<0.05$ level (Fig. 6A).

The double CORT injection ANOVA analysis revealed a significant effect of drug treatment $\left(F_{(2,28)}=4.334 ; p<0.05\right)$ and a significant interaction between the training condition and drug treatment $\left(F_{(4,28)}=6.807 ; p<0.001\right)$; post hoc Fisher's tests revealed that the sham, ADX plus double CORT, and ADXpaired groups were each significantly different from each of the control groups at the $p<0.05$ level (Fig. 6B).

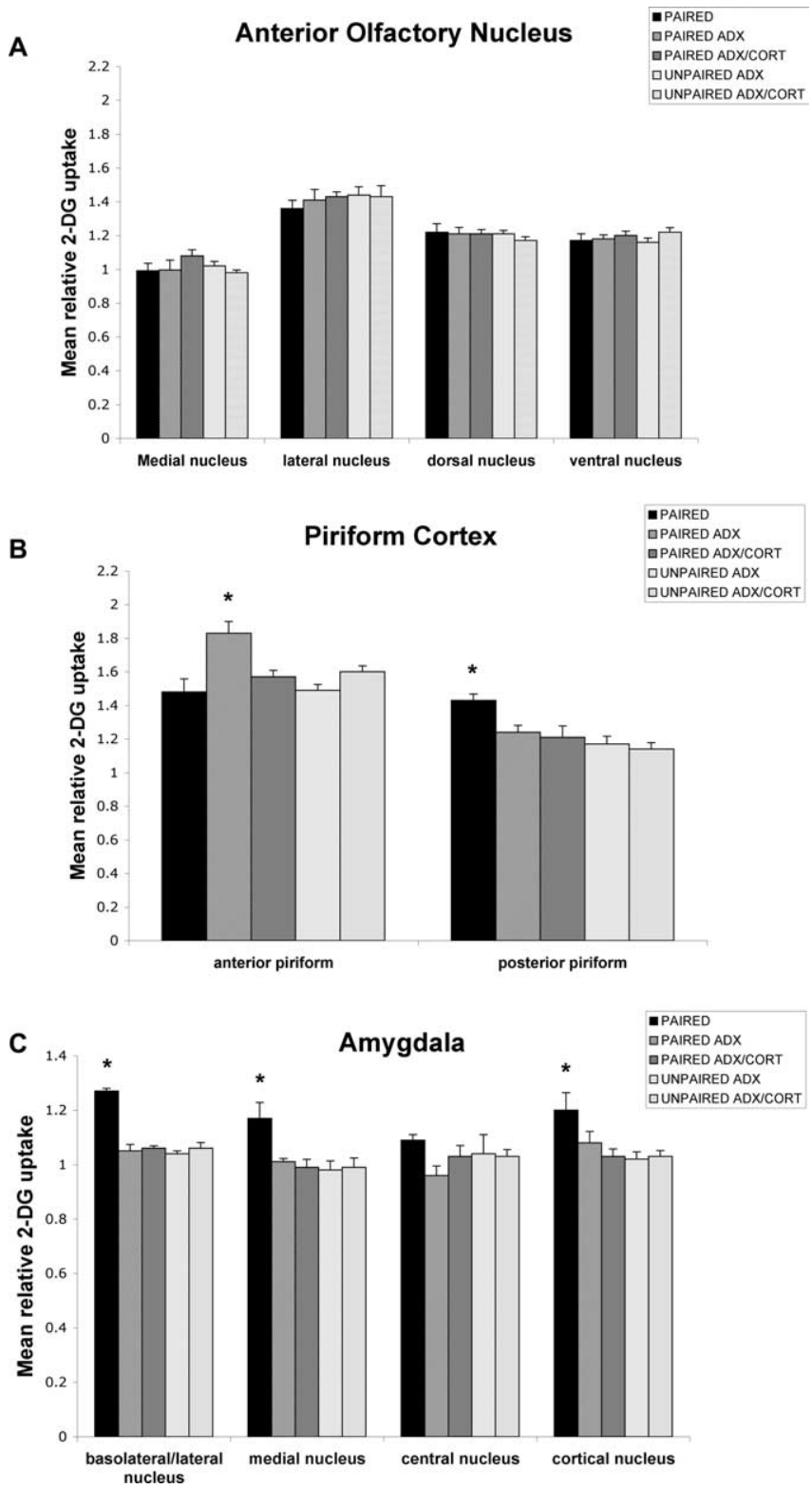

Figure 7. Effect of a single CORT injection on the 2-DG relative uptake in olfactory circuitry in the postsensitive period (P12). Error bars represent the mean ( \pm SEM) level of 2-DG uptake in the medial, lateral, dorsal, and ventral nuclei of the $\operatorname{AON}(\boldsymbol{A})$, anterior and posterior piriform cortex $(\boldsymbol{B})$, and basolateral/lateral, medial, central, and cortical nuclei of the amygdala $(\boldsymbol{C}$. ${ }^{*} p<0.05$, significant difference from all other groups.

Decreasing CORT (ADX) extends the sensitive period and alters the neural circuitry of odor-shock associative conditioning

As illustrated in Figures 7 and 8, sham-ADX-paired odor-shock pups had learning-induced enhancement of activity within the posterior piriform cortex and the amygdala (cortical, basolateral/ lateral, and medial nuclei), which replicates previous findings on the amygdala as a whole (Sullivan et al., 2000a; Roth and Sullivan, 2005) but also provides information on activity within specific amygdala nuclei. As shown in Figures 7 and 8, P12 ADX pups (ADX at P8), which permitted the learning of an odor preference rather than the age-typical odor aversion, resulted in enhanced odor-shock-induced activity within the anterior piriform cortex and blocked the age-appropriate odor-shock effects in the posterior piriform cortex and the amygdala (cortical, basolateral/ 
A
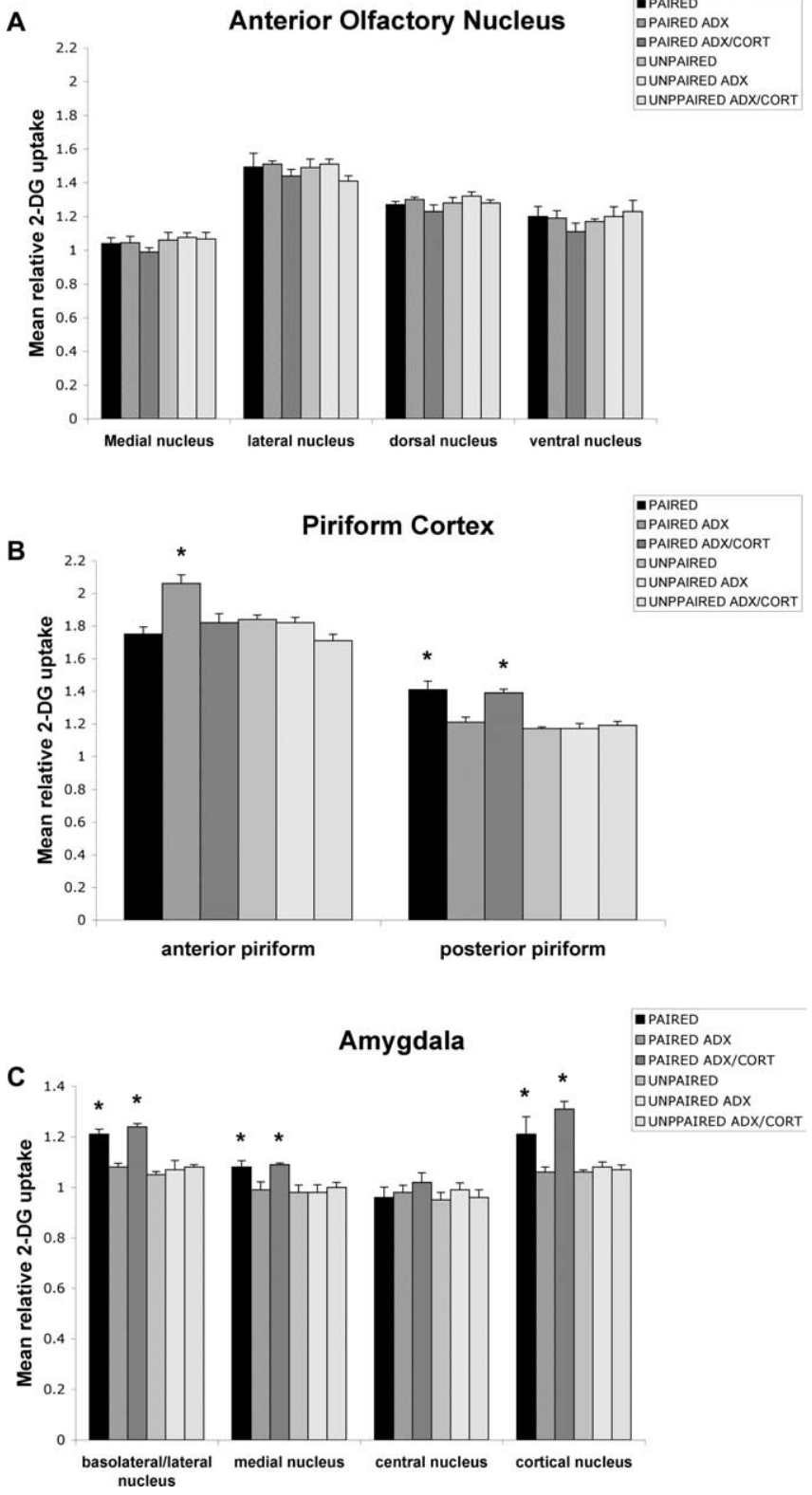

Figure 8. Effect of a double CORT injection on the 2-DG relative uptake in olfactory circuitry in the postsensitive period (P12). Error bars represent the mean ( \pm SEM) level of 2-DG uptake in the medial, lateral, dorsal, and ventral nuclei of the AON $(\boldsymbol{A})$, anterior and posterior piriform cortex $(\boldsymbol{B})$, and basolateral/lateral, medial, central, and cortical nuclei of the amygdala $(\boldsymbol{C})$. ${ }^{*} p<0.05$, significant difference from all other groups.

lateral, and medial nuclei). As illustrated in Figure 6, CORT replacement in ADX P12 pups with one injection of CORT $30 \mathrm{~min}$ before odor-shock conditioning, which permitted odoravoidance learning, prevented the learning-associated enhancement in anterior piriform cortex activity seen after ADX but did not induce aversion-associated changes in either the posterior piriform cortex or amygdala. As shown in Figure 8, CORT replacement in ADX P12 pups with double CORT injections (24 h and 30 min before conditioning), which also causes pups to learn an odor aversion, reinstated neural activity patterns in the posterior piriform cortex and the amygdala (cortical, basolateral/lateral, and medial nuclei). As illustrated in Figures 6 and 7, ADX during the postsensitive period was sufficient to activate the neural circuit associated with odor-preference learning in sensitiveperiod pups.
ADX caused a significant difference in the anterior piriform cortex $\left(F_{(5,18)}=7.856 ; p<0.001\right)$, the posterior piriform cortex $\left(F_{(5,18)}=12.976 ; p<0.0001\right)$, the basolateral/lateral amygdala $\left(F_{(5,18)}=16.132 ; p<0.0001\right)$, the medial amygdala $\left(F_{(5,16)}=\right.$ $3.776 ; p<0.05)$, and the cortical amygdala $\left(F_{(5,15)}=6.425 ; p<\right.$ 0.05). Post hoc Fisher's tests indicated that the ADX-paired groups differed significantly from each of the other paired groups and each control group at the $p<0.05$ level for the anterior piriform cortex. Additionally, the posterior piriform cortex, basolateral/lateral amygdala, medial amygdala, and cortical amygdala of sham-paired groups differed from the ADX-paired groups, the $\mathrm{ADX}$-one CORT injection replacement-paired pups, and the control groups at the $p<0.05$ level. No statistical differences were found for the AON.

A single CORT injection caused a significant increase in the anterior piriform cortical activity (Fig. 7) $\left(F_{(4,23)}=7.055 ; p<\right.$ 0.001). Post hoc Fisher's tests indicated that the ADX-paired groups differed significantly from each of the other paired groups and each control group at the $p<0.05$ level for the anterior piriform cortex. No statistical differences were found for the AON.

As illustrated in Figure 8, double CORT injection caused a significant difference compared with controls in activity of the anterior piriform cortex $\left(F_{(5,18)}=7.856 ; p<0.001\right)$, the posterior piriform cortex $\left(F_{(5,18)}=12.976 ; p<0.0001\right)$, the basolateral/ lateral amygdala $\left(F_{(5,18)}=16.132 ; p<0.0001\right)$, the medial amygdala $\left(F_{(5,16)}=3.776 ; p<0.05\right)$, and the cortical amygdala $\left(F_{(5,15)}\right.$ $=6.425 ; p<0.05)$. Post hoc Fisher's tests revealed that the anterior piriform cortex of ADX-paired pups differed from each of the other groups, whereas the sham-paired pups and ADX-double CORT injection replacement-paired pups differed from each of the other groups for the posterior piriform cortex, basolateral/ lateral amygdala, cortical amygdala, and medial amygdala at the $p<0.05$ level. No effects of training or drug condition were found within the AON.

\section{Intra-amygdala infusion of the CORT antagonist postsensitive period permits the learning of odor-preference learning}

As shown in Figure $9 A$, control pups with vehicle infused into the amygdala at the end of the sensitive period (P12) showed agetypical odor-aversion learning. However, postsensitive-period pups given $0.3 \mathrm{ng}$ of CORT antagonist directly infused into the amygdala during paired odor-shock conditioning exhibited a preference learning for the peppermint odor, whereas sensitiveperiod pups given $0.3 \mathrm{ng}$ of CORT antagonist directly infused into the caudate during paired odor-shock conditioning showed age-typical odor-aversion learning (Fig. 9B). ANOVA analysis for the amygdala infusion revealed a significant main effect of drug treatment $\left(F_{(1,25)}=28.361 ; p<0.0001\right)$ and a significant interaction between training condition and drug treatment $\left(F_{(2,25)}=\right.$ 29.563; $p<0.0001)$; post hoc Fisher's tests revealed that pups infused with $0.3 \mathrm{ng}$ of CORT antagonist into the amygdala spent significantly more time over the CS odor than each of the other groups $(p<0.05)$. ANOVA analysis for the caudate infusion revealed a significant main effect of training condition $\left(F_{(2,24)}=\right.$ 22.211; $p<0.0001)$; post hoc Fisher's tests revealed that pups infused with $0.3 \mathrm{ng}$ of CORT antagonist into the caudate still showed an odor aversion compared with the control groups $(p<$ 0.05).

Analysis of activity (first $20 \mathrm{~s}$ of odor) during odor-shock conditioning with amygdala and caudate infusion demonstrated that the acquisition curves were significantly different for trial by 
condition (data not shown; repeatedmeasure ANOVA; amygdala: $F_{(20,250)}=$ 9.662, $p<0.0001$; caudate: $F_{(20,240)}=$ $10.667, p<0.0001)$. Amygdala and caudate cannula tip placements were verified, and all tip placements were within $1 \mathrm{~mm}$ of the amygdala and targeted the basolateral nucleus, the lateral nucleus, or the central nucleus of the amygdala (Fig. 9C,D).

\section{Summary of main findings}

Supplemental Figure 1 (available at www. jneurosci.org as supplemental material) graphically summarizes the findings reported here. Sensitive-period pups or ADX postsensitive-period pups learn a preference for odors paired with shock and have odor-shock-induced activation of the early stages of the primary olfactory pathway, including the olfactory bulb and anterior piriform cortex. In contrast, postsensitive-period pups or sensitiveperiod pups given dual injections of CORT learn aversions to odors paired with shock and have odor-shock-induced activation of the posterior piriform cortex and the amygdala. Low-level injections of CORT to sensitive-period odor-shock pups, which prevents odor-preference learning but is not sufficient to support odor-aversion learning, results in no significant activation of any of these areas. CORT thus acts as a switch during early development between two different circuits underlying distinctly different learned behaviors.

\section{Discussion}

Our data suggest at least two pathways for odor-shock conditioning are present in pups, and CORT determines which pathway will be used. Indeed, the action of CORT on the amygdala appears to be critical in "deciding" which circuit will be used by incorporating the amygdala into the odor-shock learning circuit and odoravoidance learning. The ecological signif-

Figure 9. $A$, Mean ( \pm SEM) number of choices toward the $\mathrm{CS}$ odor during the Y-maze test. Training infusion of amygdala CORT antagonist permitted the learning of a relative odor preference compared with each of the other groups. $\boldsymbol{B}$, Mean ( \pm SEM) number of choices toward the CS odor during the Y-maze test. Training infusion of caudate CORT permitted the learning of a relative odor aversion compared with each of the other groups. In $\boldsymbol{A}$ and $\boldsymbol{B}$, the asterisks indicate significant differences from the control groups ( $p<0.001)$. $C$, Locations of cannula tips (solid circles) in rats used for CORT antagonist infusion into the amygdala. $\boldsymbol{D}$, Locations of cannula tips (solid circles) in rats used for CORT antagonist infusion into the caudate.
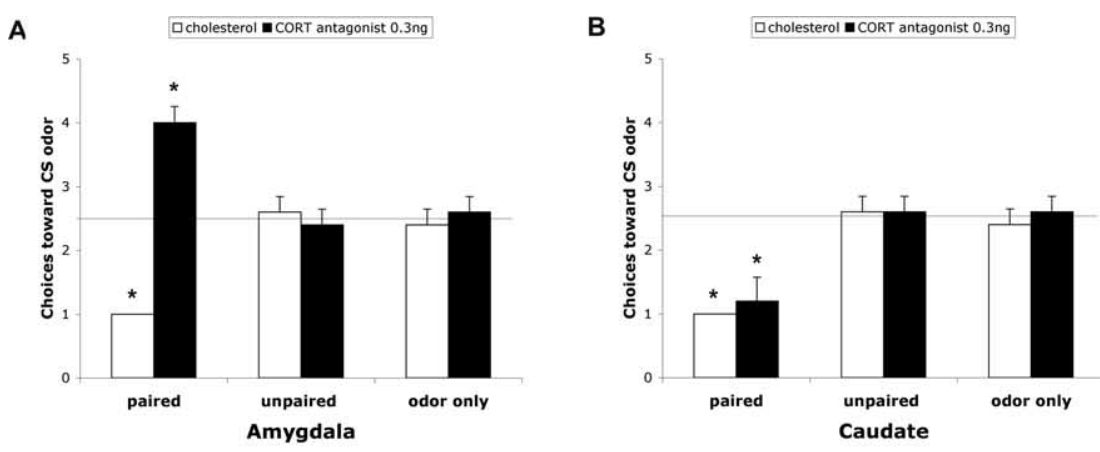

C
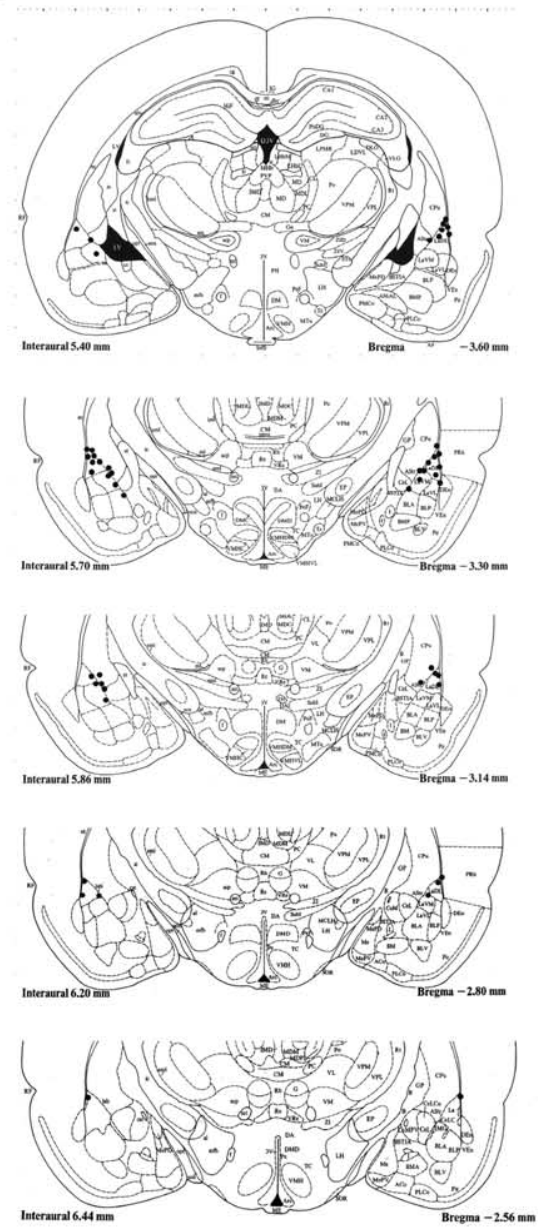

D
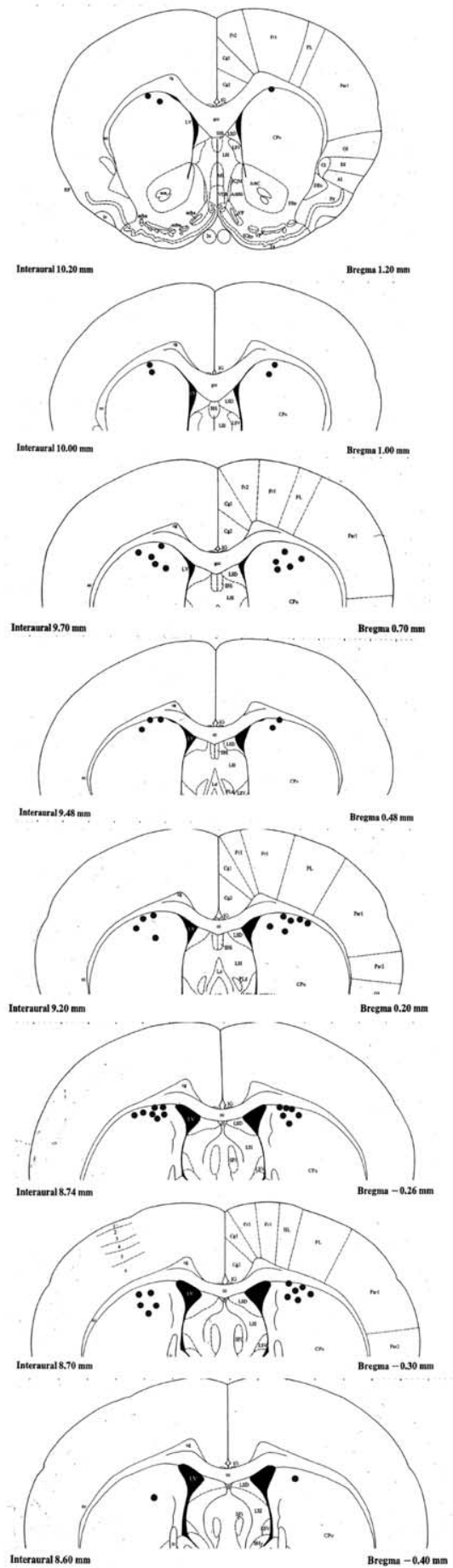
icance of this CORT-dependent learning circuit may be to enable sensitive-period pups, with naturally stable and low levels of CORT, to rapidly learn olfactory-based attachment to the mother even when interactions with the mother are painful (i.e., mother stepping on pups).

Increasing CORT either systemically or directly into the amygdala permitted the precocious ontogenetic emergence of fear conditioning in neonatal pups and induced participation of brain areas implicated in adult fear learning (posterior piriform cortex and cortical, basolateral/lateral, and medial nuclei of the amygdala). Similarly, decreasing CORT in older pups prolonged odor preference learned from odor-shock conditioning and maintained or reactivated the unique neural circuitry involved in sensitive-period preference learning (increased olfactory bulb activity and anterior piriform cortex neural activity) (Moriceau and Sullivan, 2004b; Roth and Sullivan, 2005).

Although only one injection of CORT 30 min before conditioning blocked learning and all neural correlates associated with either preference or avoidance learning from odor-shock conditioning, two injections were able to evoke the adult-like fear conditioning and its related circuitry. The more prolonged twoinjection treatment with CORT required to induce adult-like fear conditioning suggests altered gene expression may be required for the switch to be expressed. Indeed, nuclear CORT receptors move to the cytoplasm under low CORT conditions (e.g., sensitive-period, CORT hypo-responsive aged pups) and take time to return to the nuclear membrane when CORT increases (Borski, 2000; Orchinik et al., 2002; De Kloet, 2004). However, although a single systemic injection was insufficient to induce adult-like aversion learning, a single infusion of CORT directly into the amygdala during conditioning rapidly enabled pups to learn an odor aversion and altered the neural circuitry. The failure of the postsensitive-period ADX CORT replacement group to show amygdala activation, yet learn an odor aversion, suggests nonamygdala pathways for odor aversion exist. Although the olfactory bulb has been shown previously to code odor aversions and preferences in pups, this area is not coding for the learned odor aversion in the postsensitive period ADX CORT pups (McLean et al., 1999; Zhang et al., 2003; Moriceau and Sullivan, 2004). These pups may be using the nonamygdala odor-aversion pathway, although this needs to be more carefully assessed in pups (Poulos and Fanselow, 2005).

\section{Adult and infant circuits for odor-shock conditioning}

The adult fear-conditioning literature suggests adults have multiple pathways to the amygdala that could support learned fear (LeDoux et al., 1984; Shi and Davis, 1999). Additionally, fear conditioning both with and without amygdala involvement has been documented in adult rats (Cahill et al., 1999; Doron and LeDoux, 1999; Fanselow and LeDoux, 1999; Sullivan et al., 2000a; Goosens and Maren, 2001; Schafe et al., 2001; Wallace and Rosen, 2001; Walker and Davis, 2002; Fanselow and Gale, 2003; Maren, 2003; McGaugh 2004, Poulos and Fanselow, 2005). However, in sharp contrast to these adult odor-shock fear circuits, where the adult animal always learns fear-related behaviors, our pups learn either a fear-associated odor aversion or an odor preference with odor-shock conditioning using two distinct pathways.

During the middle preweanling period assessed here, the odor-shock learning circuit seems to be dependent on the CORT level, not the pups' age. This suggests neuroanatomical maturation and connectivity are not primary critical factors. CORTassociated changes were found in multiple brain areas along the olfactory pathway, all of which contain CORT receptors, suggest- ing the action of CORT on modifying the fear-learning circuit could occur in multiple brain areas (Sousa et al., 1989; Alexis et al., 1990; Morimoto et al., 1996).

\section{The site of CORT action is the amygdala}

Although CORT-induced learning changes were evident in multiple brain areas, our intra-amygdala CORT manipulation was sufficient to induce fear conditioning in pups (Price, 1973; Meredith, 1991; Aggleton, 2001; Ferguson et al., 2001; McDonald, 2003; for review, see Wilson and Sullivan, 2003). The amygdala has a high density of CORT receptors, and glucocorticoids modulate excitability and synaptic transmission of amygdala neurons (Stutzmann et al., 1998; Karst et al., 2002; Roozendaal et al., 2002). Thus, modulation of CORT levels could and does directly modulate amygdala involvement during odorshock conditioning in preweanlings as shown here. Importantly, however, the amygdala also projects widely to other limbic and olfactory system structures (Pitkanen et al., 2003) and has been shown to be a critical modulator of plasticity in those projection targets. For example, adult hippocampal long-term potentiation can be modulated by CORT levels and/or stress, but only if the amygdala is intact (Korz and Frey, 2005). Via these projections, therefore, the amygdala could serve as a CORT-mediated switch not only for its own intrinsic excitability and plasticity, but also for the other components of the attraction and aversion circuits in the preweanling olfactory system.

Furthermore, the ability of both systemic and intra-amygdala CORT infusions to alter odor-aversion learning suggests the failure of the amygdala to become incorporated into the fear circuit is not attributable to immaturity per se. Rather, the infant amygdala seems dependent on a signal (CORT) to activate a "dormant" amygdala to become incorporated into the pups' fearconditioning circuit and permit odor-aversion learning. A similar critical role for CORT was found for the ontogeny of unlearned fear (predator odor) in rat pups, which also emerges at P10 (Takahashi, 1992, 1994; Takahashi and Rubin, 1993; Wiedenmayer and Barr, 2001), and is correlated with amygdala activation (Moriceau et al., 2004). The convergence of the role of CORT and the amygdala in learned and unlearned fear strengthens our working hypothesis of a causal relationship between these variables.

It is also possible that CORT could modulate fear conditioning through corticotrophin-releasing hormone $(\mathrm{CRH})$ producing neurons within the amygdala. In contrast to the more general negative feedback action of the glucocorticoids within the amygdala, there seems to be a feedforward regulation of CRH within the central amygdala (Schulkin et al., 2005). Because clearance of CORT is delayed in the developing hypothalamic-pituitary-adrenal axis, prolonged exposure to CORT may result in an upregulation of CRH. However, at least in adults, the primary target for CORT-mediated upregulation of CRH is the central amygdala, although changes in this brain area were not detected in the present experiments. $\mathrm{CRH}$ gene expression in the amygdala does show a marked increase between P6 and P12 (D. M. Vazquez, C. Bailey, D. K. Okimoto, G. W. Dent, A. Steffek, L. F. Lopez, and S. Levine, unpublished data), but the specific nuclei were not examined.

Although our data suggest direct action of CORT on the amygdala as the critical site of the pups' odor-aversion learning, other possible sites for CORT effects also exist. Specifically, there are indirect olfactory inputs to the cortical amygdala via both the anterior and posterior piriform cortex and to the basolateral/ lateral amygdala via the posterior piriform cortex (Price, 1973; 
Schwob and Price, 1984; Shipley et al., 1985; Haberly, 2001; McDonald, 2003; Pitkanen et al., 2003; for review, see Wilson and Sullivan, 2003). Our data show CORT shifts learning-induced changes between the anterior and posterior piriform cortex, suggesting input to the amygdala is altered by CORT. In adults, both the anterior and posterior piriform cortex appear to be involved in learning, but the posterior piriform cortex may be more strongly implicated in associative memory processes (Hasselmo and Barkai, 1995; Litaudon et al., 1997; Barkai and Sahar, 2001; Haberly, 2001; Mouly et al., 2001; Tronel and Sara, 2002; Best et al., 2004; Sevelinges et al., 2004; Wilson et al., 2004).

\section{Contrasting role of CORT in infants and adults}

CORT has unique effects in pups because it alters whether pups learn an aversion or preference from odor-shock conditioning. This is in sharp contrast to adult CORT effects in which CORT enhances/attenuates fear-conditioning and inhibitory conditioning, but CORT blockade does not lead to a hedonic reversal and resulting preference (Corodimas et al., 1994; Roozendaal et al., 1996, 2002; Pugh et al., 1997; Hui et al., 2004; Thompson et al., 2004). We have hypothesized previously (Wilson and Sullivan, 1994) that the unique characteristics of the neonatal noradrenergic system may create a default odor preference tendency in neonates. As this default preference system fades and the CORT system matures at the end of the sensitive period, learned preferences are no longer expressed in CORT-impaired adults.

\section{Ecological significance: CORT and maternal behavior}

The ability of CORT to alter sensitive-period termination and determine the odor-shock neural pathway is related to the stress hyporesponsive period, when the pups' CORT is unaffected by most stressful stimuli (i.e., restraint, shock) (Rosenfeld et al., 1992; Grino et al., 1994; Levine, 2001). The stress hyporesponsive period declines as the sensitive period ends, suggesting the naturally occurring CORT system change underlies sensitive-period termination. Moreover, maternal behavior influences the pups' CORT level in which sensory stimulation provided by the mother during nursing and grooming maintains the pups' low CORT level throughout the stress hyporesponsive period (Van Oers et al., 1998). This maternal influence continues after the stress hyporesponsive period terminates, because maternal stimuli continue to reduce the pups' CORT release to stressful and painful stimuli (Stanton and Levine, 1990; Suchecki et al., 1993). Furthermore, the ability of the environment (stress, CORT passed through milk, maternal presence, etc.) to modify the pups' CORT level suggests both learned and unlearned fear in pups can be modified to fit environmental demands.

\section{References}

Aggleton JP (2001) The amygdala: a functional analysis, Ed 2. London: Oxford UP.

Alexis MN, Kitraki E, Spanou K, Stylianopoulou F, Sekeris C (1990) Ontogeny of the glucocorticoid receptor in the rat brain. Adv Exp Med Biol 265:269-276.

Barkai E, Saar D (2001) Cellular correlates of olfactory learning in the rat piriform cortex. Rev Neurosci 12:111-120.

Barr GA (1995) Ontogeny of nociception and antinociception. NIDA Res Monograph 158:172-201.

Berdel B, Morys J (2000) Expression of calbindin-D28k and parvalbumin during development of rat's basolateral amygdaloid complex. Int J Dev Neurosci 18:501-513

Berdel B, Morys J, Maciejewska B (1997) Neuronal changes in the basolateral complex during development of the amygdala of the rat. Int J Dev Neurosci 15:755-765.

Best AR, Thompson JV, Fletcher ML, Wilson DA (2004) Cortical metabo- tropic glutamate receptors contribute to habituation of a simple odorevoked behavior. J Neurosci 25:2513-2517.

Bialik RJ, Pappas BA, Roberts DC (1984) Neonatal 6-hydroxydopamine prevents adaptation to chemical disruption of the pituitary-adrenal system in the rat. Horm Behav 18:12-21.

Blozovski D, Cudennec A (1980) Passive avoidance learning in the young rat. Dev Psychobiol 13:513-518.

Borski RJ (2000) Nongenomic membrane actions of glucocorticoids in vertebrates. Trends Endocrinol Metab 11:427-436.

Bouwmeester H, Smits K, Van Ree JM (2002) Neonatal development of projections to the basolateral amygdala from prefrontal and thalamic structures in rat. J Comp Neurol 450:241-255.

Cahill L, Weinberger NM, Roozendaal B, McGaugh JL (1999) Is the amygdala a locus of "conditioned fear"? Some questions and caveats. Neuron 23:227-228.

Camp LL, Rudy JW (1988) Changes in the categorization of appetitive and aversive events during postnatal development of the rat. Dev Psychobiol 21:25-42.

Collier AC, Mast J, Meyer DR, Jacobs CE (1979) Approach-avoidance conflict in preweanling rats: a developmental study. Anim Learn Behav 7:514-520.

Conrad CD, MacMillan II DD, Tsekhanov S, Wright RL, Baran SE, Fuchs RA (2004) Influence of chronic corticosterone and glucocorticoid receptor antagonism in the amygdala on fear conditioning. Neurobiol Learn Mem 81:185-199.

Coopersmith R, Leon M (1986) Enhanced neural response by adult rats to odors experienced early in life. Brain Res 371:400-403.

Corodimas KP, LeDoux JE, Gold PW, Schulkin J (1994) Corticosterone potentiation of conditioned fear in rats. Ann NY Acad Sci 746:392-393.

De Kloet ER (2004) Hormones and stresses brain. Ann NY Acad Sci 1018:1-15.

Dent GW, Smith MA, Levine S (1999) The ontogeny of the neuroendocrine response to endotoxin. Dev Brain Res 117:21-29.

DiRocco RJ, Hall WG (1981) Metabolic neural mapping in neonatal rats. J Neurosci Res 6:13-19.

Donley MP, Shulkin J, Rosen JB (2005) Glucocorticoid receptor antagonist in the basolateral amygdala and ventral hippocampus interferes with long-term memory of contextual fear. Behav Brain Res 164:197-205.

Doron NN, LeDoux JE (1999) Organization of projections to the lateral amygdala from auditory and visual areas of the thalamus in rat. J Comp Neurol 412:383-409.

Emerich DF, Scalzo FM, Enters EK, Spear N, Spear L (1985) Effects of 6-hydroxydopamine-induced catecholamine depletion on shockprecipitated wall climbing of infant rat pups. Dev Psychobiol 18:215-227.

Fanselow MS, Gale GD (2003) The amygdala, fear, and memory. Ann NY Acad Sci 985:125-134

Fanselow MS, LeDoux JE (1999) Why we think plasticity underlying Pavlovian fear conditioning occurs in the basolateral amygdala. Neuron 23:229-232.

Ferguson JN, Aldag JM, Insel TR, Young LJ (2001) Oxytocin in the medial amygdala is essential for social recognition in the mouse. J Neurosci 21:8278-8285.

Grino M, Paulmyer-Lacroix O, Faudon M, Renard M, Anglade G (1994) Blockade of alpha 2-adrenoreceptors stimulates basal and stress-induced adrenocorticotropin secretion in the developing rat through a central mechanism independent from corticotropin-releasing factor and arginine vasopressin. Endocrinology 135:2549-2557.

Goosens KA, Maren S (2001) Contextual and auditory fear conditioning are mediated by the lateral, basal, and central amygdaloid nuclei in rats. Learn Mem 8:148-155.

Haberly LB (2001) Parallel-distributed processing in olfactory cortex: new insights from morphological and physiological analysis of neuronal circuitry. Chem Senses 26:551-576.

Hall WG (1979) Feeding and behavioral activation in infant rats. Science 205:206-209.

Harlow HF, Harlow MK (1965) The affectional systems. In: Behavior of nonhuman primates, Vol 2 (Schrier A, Harlow HF, Stollnitz F, eds), pp 287-334. New York: Academic.

Hasselmo ME, Barkai E (1995) Cholinergic modulation of activitydependent synaptic plasticity in the piriform cortex and associative memory function in a network biophysical simulation. J Neurosci 15:6592-6604. 
Helfer ME, Kempe RS, Krugman RD (1997) The battered child. Chicago: University of Chicago.

Hess EH (1962) Ethology: an approach to the complete analysis of behavior. In: New directions in psychology (Brown R, Galanter E, Hess EH, Mendler G, eds), pp 159-199. New York: Holt, Rinehart and Winston.

Hui GK, Figueroa IR, Poytress BS, Roozendaal B, McGaugh JL, Weinberger NM (2004) Memory enhancement of classical fear conditioning by post-training injections of corticosterone in rats. Neurobiol Learn Mem 81:67-74.

Karst H, Nair S, Velzing E, Rumpff-van Essen L, Slagter E, Shinnick-Gallagher P, Joëls M (2002) Glucocorticoids alter calcium conductances and calcium channel subunit expression in basolateral amygdala neurons. Eur J Neurosci 16:1083-1089.

Korz V, Frey JU (2005) Bidirectional modulation of hippocampal longterm potentiation under stress and no-stress conditions in basolateral amygdala-lesioned and intact rats. J Neurosci 25:7393-7400.

LeDoux JE, Sakaguchi A, Reis DJ (1984) Subcortical efferent projections of the medial geniculate nucleus mediate emotional responses conditioned to acoustic stimuli. J Neurosci 4:683-698.

Levine S (2001) Primary social relationships influence the development of the hypothalamic-pituitary-adrenal axis in the rat. Physiol Behav 73:255-260.

Litaudon P, Mouly AM, Sullivan RM, Gervais R, Catarelli M (1997) Learning-induced changes in rat piriform cortex activity mapped using multisite recording with voltage sensitive dye. Eur J Neurosci 9:1593-1602.

Maren S (2003) The amygdala, synaptic plasticity, and fear memory. Ann NY Acad Sci 985:106-113.

McDonald AJ (2003) Is there an amygdala and how far does it extend? An anatomical perspective. Ann NY Acad Sci 985:1-21.

McGaugh JL (2004) The amygdala modulates the consolidation of memories of emotionally arousing experiences. Annu Rev Neurosci 27:1-28.

McLean JH, Harley CW, Darby-King A, Yuan Q (1999) pCREB in the neonate rat olfactory bulb is selectively and transiently increased by odor preference-conditioned training. Learn Mem 6:608-618.

Meaney MJ, Sapolsky RM, Aitken DH, McEwen BS (1988) [ $\left.{ }^{3} \mathrm{H}\right]$ dexamethasone binding in the limbic brain of the fetal rat. Brain Res 355:297-300.

Meredith M (1991) Sensory processing in the main and accessory olfactory systems: comparisons and contrasts. J Steroid Biochem Mol Biol 36:601-614.

Moriceau S, Sullivan RM (2004a) Unique neural circuitry for neonatal olfactory learning. J Neurosci 24:1182-1189.

Moriceau S, Sullivan RM (2004b) Corticosterone influences on mammalian neonatal sensitive period learning. Behav Neurosci 118:274-281.

Moriceau S, Roth TL, Okotoghaide T, Sullivan RM (2004) Corticosterone controls the developmental emergence of fear and amygdala function to predator odors in infant rat pups. Int J Dev Neurosci 22:415-422.

Morimoto M, Morita N, Ozawa H, Yokoyama K, Kawata M (1996) Distribution of glucocorticoid receptor immunoreactivity and mRNA in the rat brain: an immunohistochemical and in situ hybridization study. Neurosci Res 26:235-269.

Morys J, Berdel B, Jagalska-Majewska H, Luczynska A (1999) The basolateral amygdaloid complex-its development, morphology and functions. Folia Morphol 58:29-46.

Mouly M, Fort A, Ben-Boutayab N, Gervais R (2001) Olfactory learning induces differential long-lasting changes in rat central olfactory pathways. Neuroscience 102:11-21.

Myslivecek J (1997) Inhibitory learning and memory in newborn rats. Prog Neurobiol 53:399-430.

Nair HP, Gonzalez-Lima F (1999) Extinction of behavior in infant rats: development of functional coupling between septal, hippocampal and ventral tegmental regions. J Neurosci 19:8646-8655.

Nudo RJ, Masterton RB (2004) Stimulation-induced $\left[{ }^{14} \mathrm{C}\right] 2$-deoxyglucose labeling of synaptic activity in the central auditory system. J Comp Neurol 245:553-565.

Orchinik M, Gasser P, Breuner C (2002) Rapid corticosteroid actions on behavior. Horm Brain Behav 3:567-600.

Paxinos G, Tork I, Tecott LH, Valentino KL (1991) Atlas of the developing rat brain. San Diego: Academic.

Pitkanen A, Savander M, Nurminen N, Ylinen A (2003) Intrinsic synaptic circuitry of the amygdala. Ann NY Acad Sci 985:34-49.

Poulos AM, Fanselow MS (2005) Lesions of the bed nucleus of the stria terminalis disrupt expression contextual fear in intact or basolateral nucleus of the amygdala lesioned rats. Soc Neurosci Abstr 31:414.24.

Price JL (1973) An autoradiographic study of complementary laminar patterns of termination of afferent fibers to the olfactory cortex. J Comp Neurol 150:87-108.

Pugh CR, Tremblay D, Fleshner M, Rudy JW (1997) A selective role for corticosterone in contextual fear conditioning. Behav Neurosci 111:03-511.

Rajecki DW, Lamb ME, Obmascher P (1978) Towards a general theory of infantile attachment: a comparative review of aspects of the social bond. Behav Brain Sci 3:417-464.

Richardson R, Siegel MA, Campbell BA (1989) Effect of maternal presence on the cardiac and behavioral responses to shock in rats as a function of age. Dev Psychobiol 22:567-583.

Roozendaal B, Bohus B, McGaugh JL (1996) Dose-dependent suppression of adrenocortical activity with metyrapone: effects on emotion and memory. Psychoneuroendocrinology 21:681-693.

Roozendaal B, Quirarte GL, McGaugh JL (2002) Glucocorticoids interact with the basolateral amygdala beta-adrenoceptor-cAMP/cAMP/PKA system in influencing memory consolidation. Eur J Neurosci 55:553-560.

Rosenfeld P, Van Eekelen JA, Levine S, De Kloet ER (1988) Ontogeny of the type 2 glucocorticoid receptor in discrete rat brain regions: an immunocytochemical study. Brain Res 470:119-127.

Rosenfeld P, Suchecki D, Levine S (1992) Multifactorial regulation of the hypothalamic-pituitary-adrenal axis during development. Neurosci Biobehav Rev 16:553-568.

Rosenfeld P, Van Eekelen JAM, Levine S, De Kloet ER (1993) Ontogeny of corticosteroid receptors in the brain. Cell Mol Neurobiol 13:295-319.

Roth TL, Sullivan RM (2005) Memory of early maltreatment: neonatal behavioral and neural correlates of maternal maltreatment within the context of classical conditioning. Biol Psychiatry 57:823-831.

Schafe GE, Nader K, Blair HT, LeDoux JE (2001) Memory consolidation of Pavlovian fear conditioning: a cellular and molecular perspective. Trends Neurosci 24:540-546.

Schwob JE, Price JL (1984) The development of axonal connections in the central olfactory system of rats. J Comp Neurol 223:177-202.

Schulkin J, Morgan MA, Rosen JB (2005) A neuroendocrine mechanism for sustaining fear. Trends Neurosci 28:629-635.

Sevelinges Y, Gervais R, Messaoudi B, Granjon L, Mouly AM (2004) Olfactory fear conditioning induces field potential potentiation in rat olfactory cortex and amygdala. Learn Mem 11:761-769.

Shipley MT, Halloran FJ, De la Torre J (1985) Surprisingly rich projection from locus coeruleus to the olfactory bulb in the rat. Brain Res 239:294-299.

Shi C, Davis M (1999) Pain pathways involved in fear conditioning measured with fear-potentiated startle: lesion studies. J Neurosci 19:420 -430.

Sousa RJ, Tannery NH, Lafer EM (1989) In situ hybridization mapping of glucocorticoid receptor messenger ribonucleic acid in rat brain. Mol Endocrinol 3:481-494.

Stanton ME, Levine S (1990) Inhibition of infant glucocorticoid stress response: specific role of maternal cues. Dev Psychobiol 23:411-426.

Stehouwer DJ, Campbell BA (1978) Habituation of the forelimbwithdrawal response in neonatal rats. J Exp Psychol Anim Behav Processes 4:104-119.

Stutzmann G, McEwen B, LeDoux J (1998) Serotonin modulation of sensory inputs to the lateral amygdala: dependency on corticosterone. J Neurosci 18:9529-9538.

Suchecki D, Mozaffarian D, Gross G, Rosenfeld P, Levine S (1993) Effects of maternal deprivation on the ACTH stress response in the infant rat. Neuroendocrinology 57:204-212.

Sullivan RM, Wilson DA (1991) Neural correlates of conditioned odor avoidance in infant rats. Behav Neurosci 105:307-312.

Sullivan RM, Wilson DA (1993) Role of the amygdala complex in early olfactory associative learning. Behav Neurosci 107:254-263.

Sullivan RM, Wilson DA (1995) Dissociation of behavioral and neural correlates of early associative learning. Dev Psychobiol 28:213-219.

Sullivan RM, Hofer MA, Brake SC (1986a) Olfactory-guided orientation in neonatal rats is enhanced by a conditioned change in behavioral state. Dev Psychobiol 19:615-623.

Sullivan RM, Brake SC, Hofer MA, Williams CL (1986b) Huddling and independent feeding of neonatal rats can be facilitated by a conditioned change in behavioral state. Dev Psychobiol 19:625-635. 
Sullivan RM, Zyzak DR, Skierkowski P, Wilson DA (1992) The role of olfactory bulb norepinephrine in early olfactory learning. Dev Brain Res 70:279-282.

Sullivan RM, Wilson DA, Lemon C, Gerhardt GA（1994） Bilateral 6-OHDA lesions of the locus coeruleus impair associative olfactory learning in newborn rats. Brain Res 643:306-309.

Sullivan RM, Landers M, Yeaman B, Wilson DA (2000a) Good memories of bad events in infancy: ontogeny of conditioned fear and the amygdala. Nature 407:38-39.

Sullivan RM, Stackenwalt G, Nasr F, Lemon C, Wilson DA (2000b) Association of an odor with activation of olfactory bulb noradrenergic betareceptors or locus coeruleus stimulation is sufficient to produce learned approach responses to that odor in neonatal rats. Behav Neurosci 114:957-962.

Takahashi LK (1992) Ontogeny of behavioral inhibition induced by unfamiliar adult male conspecifics in pre-weanling rats. Physiol Behav 52:493-498.

Takahashi LK (1994) Organizing action of corticosterone on the development of behavioral inhibition in the preweanling rat. Dev Brain Res 81:121-127.

Takahashi LK, Rubin WW (1993) Corticosteroid induction of threatinduced behavioral inhibition in preweanling rats. Behav Neurosci 107:860-866.

Takahashi LK, Turner JG, Kalin NH (1991) Development of stress induced responses in preweanling rats. Dev Psychobiol 24:341-360.

Thompson BL, Erickson K, Schulkin J, Rosen JB (2004) Corticosterone facilitates retention of contextually conditioned fear and increases $\mathrm{CRH}$ mRNA expression in the amygdala. Behav Brain Res 149:209-215.

Tronel S, Sara SJ (2002) Mapping of olfactory memory circuits: regionspecific c-fos activation after odor-reward associative learning or after its retrieval. Learn Mem 9:105-111.
Tucker DL, Tucker N, Conway T (2002) Gene expression profiling of the pH response in E. coli. J Bacteriol 183:6551-6558.

Van Oers HJJ, de Kloet ER, Whelan T, Levine S (1998) Maternal deprivation effect on the infant's neural stress markers is reversed by tactile stimulation and feeding but not by suppressing corticosterone. J Neurosci 18:10171-10179.

Walker DL, Davis M (2002) The role of amygdala glutamate receptors in fear learning, fear-potentiated startle, and extinction. Pharmacol Biochem Behav 71:379-392.

Wallace KJ, Rosen JB (2001) Neurotoxic lesions of the lateral nucleus of the amygdala decrease conditioned fear but not unconditioned fear of a predator odor: comparison with electrolytic lesions. J Neurosci 21:3619-3627.

Wiedenmayer CP, Barr GA (2001) Developmental changes in c-fos expression to an age-specific social stressor in infant rats. Behav Brain Res 126:147-157.

Wilson DA, Sullivan RM (1994) Neurobiology of associative learning in the neonate: early olfactory learning. Behav Neural Biol 61:1-18.

Wilson DA, Sullivan RM (2003) Sensory physiology of central olfactory pathways. In: Handbook of olfaction and gestation, Ed 2 (Doty R, ed), pp 181-201. New York: Marcel Dekker.

Wilson DA, Fletcher ML, Sullivan RM (2004) Acetylcholine and olfactory perceptual learning. Learn Mem 11:28-34.

Winkler RL, Hays WL (1975) Sampling theory, experimental design, and analysis of variance. In: Statistics probability, interference and decision, pp 782-783.

Yang YL, Chao PK, Lu KT (2005) Systemic and intra-amygdala administration of glucocorticoid agonist and antagonist modulate extinction of conditioned fear. Neuropsychopharmacology 31:912-924.

Zhang JJ, Okutani F, Inoue S, Kaba H (2003) Activation of the cyclic AMP response element-binding protein signaling pathway in the olfactory bulb is required for the acquisition of olfactory aversive learning in young rats. Neuroscience 117:707-713. 